\title{
Microcontroller-Based Lead-Acid Battery Balancing System for Electric Vehicle Applications
}

\author{
Ali Rospawan, Joni Welman Simatupang * \\ Electrical Engineering Study Program, Faculty of Engineering \\ President University \\ Jl. Ki Hajar Dewantara, Jababeka Education Park, Cikarang Baru, Jawa Barat -17530 \\ Cikarang, Indonesia
}

\begin{abstract}
In application of lead-acid batteries for electrical vehicle applications, $48 \mathrm{~V}$ of four $12 \mathrm{~V}$ batteries in a series configuration are required. However, the battery stack is repeatedly charged and discharged during operation. Hence, differences in charging and discharging speeds may result in a different state-of-charge of battery cells. Without proper protection, it may cause an excessive discharge that leads to premature degradation of the battery. Therefore, a lead-acid battery requires a battery management system to extend the battery lifetime. Following the LTC3305 balancing scheme, the battery balancing circuit with auxiliary storage can employ an imbalance detection algorithm for sequential battery. It happens by comparing the voltage of a battery on the stack and the auxiliary storage. In this paper, we have replaced the function of LTC3305 by a NUCLEO F767ZI microcontroller, so that the balancing process, the battery voltage, the drawn current to or from the auxiliary battery, and the surrounding temperature can be fully monitored. The prototype of a microcontroller-based lead-acid battery balancing system for electrical vehicle application has been fabricated successfully in this work. The batteries voltage monitoring, the auxiliary battery drawn current monitoring, the overcurrent and overheat protection system of this device has also successfully built. Based on the experimental results, the largest voltage imbalance is between battery 1 and battery 2 with a voltage imbalance of $180 \mathrm{mV}$. This value is still higher than the target of voltage imbalance that must be lower than $12.5 \mathrm{mV}$. The balancing process for the timer mode operation is faster 1.5 times compared to the continuous mode operation. However, there were no overcurrent or overtemperature occurred during the balancing process for both timer mode and continuous mode operation. Furthermore, refinement of this device prototype is required in the future to improve the performance significantly.
\end{abstract}

Keywords: Battery balancing system, electric vehicle, LTC3305, microcontroller, NUCLEO F767ZI, voltage imbalance.

\section{INTRODUCTION}

In the electric vehicle application, four $12 \mathrm{~V}$ batteries of lead-acid batteries connected in a series stack configuration are commonly employed to provide $48 \mathrm{~V}$ of the required voltage [1]- [5]. Each battery comes with different internal parameter, e.g., initial charge capacities, cell compounds, and other external effects. In addition, the battery on the stack is repeatedly charged and discharged during operation. Hence, the differences in charge-discharge speed may result in different stateof-charge in the battery cells. Without proper protection, this may cause an excessive discharge of lead-acid batteries and leads to premature degradation to the battery. Therefore, the lead-acid battery requires a battery management system to extend battery life [1]- [5].

LTC3305 is an integrated circuit developed by Linear Technology Corporation which is specifically designed to be used as the controller for balancing four or more $12 \mathrm{~V}$ lead-acid batteries connected in series configuration [1], [6].

The objective of this research is to build a prototype of the microcontroller-based lead-acid battery

\footnotetext{
* Corresponding Author.

Email: joniwsmtp@president.ac.id

Received: October 08, 2021 ; Revised: November 29, 2021

Accepted: December 20, 2021 ; Published: December 31, 2021

Open access under CC-BY-NC-SA

(C) 2021 PPET - LIPI
}

management system by replacing the function of LTC3305 with a NUCLEO F767ZI microcontroller so that the balancing process, the battery voltage, the drawn current to or from the auxiliary battery, and the surrounding temperature can be fully monitored, and the obtained values can be displayed real-time on the LCD2004 display.

This work is outlined as follows: a review of battery balancing technique which discuss the basic theory underlying the battery balancing process including the main concept of LTC3305 balancing technique. Design and Implementation section describes the proposed design, the details about usage in the system, and how the proposed design work. The Experimental Result and Discussion sections discuss the research results, and finally the conclusion of this work will be given.

\section{BATTERY BalanCING SySTEM}

\section{A. Battery Balancing Technique (General)}

Technique for battery balancing system is classified into 2 types: a passive and an active balancing technique. A passive battery balancing technique uses resistors as loads to balance the cell energy of a battery pack by discharging the excess energy or by consuming parts of energy of the higher energy cell. Although this passive battery balancing technique is easy to implement, its energy transmission efficiency is usually low due to energy losses generated by heat dissipation from the resistors [1]- [12]. 
On the other hand, an active battery balancing technique transfers energy from higher cell energy to lower cell energy using a power electronic interface, yielding a high efficiency. Although this active technique balancer has higher efficiency than a passive technique of battery balancer, its control algorithm is considered complex, and its production cost is expensive because each cell should be connected with an additional power electronics interface [1]- [12].

\section{B. LTC3305 Balancing Technique}

The LTC3305 balances four or more $12 \mathrm{~V}$ lead-acid batteries in a series configuration. It uses an auxiliary battery or an alternative storage cell to transfer charge to and from individual batteries within a series-connected stack. The balancing process of this technique uses 10 gates or switches to transfer the energy [1], [6]. The detail of its arrangement is shown in Figure 1.

The LTC3305 has two operation modes: timer mode and continuous mode. The balancing process for timer mode operation begins with the connection of the bottom switch of battery 1 on the stack to the auxiliary battery. At this step, N9 and N1 switches needs to be turned on. After the internal timer reaches $35 \mathrm{~ms}$, the voltage comparator sensor starts to compare the voltage between battery 1 and the auxiliary battery, then depends on the certain voltage differentiation values, leads to the termination voltage [1], [6], [12].

If the voltage differentiation is less than chosen termination voltage, the battery will deem then the bottom switch is turned off [1], [6]. The top and bottom switch arrangements are given in Table 1.

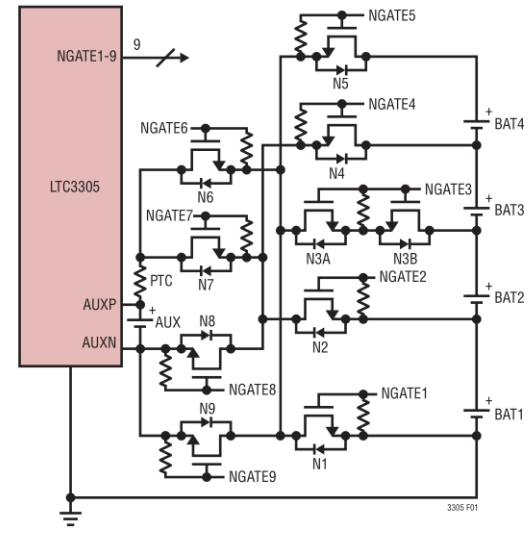

Figure 1. LTC3305 Configuration [6]

TABLE 1

TOP AND BOTTOM SWITCHES ARRANGEMENT FOR FOUR BATTERIES [1], [6].

\begin{tabular}{|c|c|c|}
\hline $\begin{array}{c}\text { Battery to } \\
\text { be } \\
\text { Balanced }\end{array}$ & Top Switch & Bottom Switch \\
\hline Battery 1 & NGATE7, NGATE2 & NGATE9, NGATE1 \\
\hline Battery 2 & NGATE6, NGATE3 & NGATE8, NGATE2 \\
\hline Battery 3 & NGATE7, NGATE4 & NGATE9, NGATE3 \\
\hline Battery 4 & NGATE6, NGATE5 & NGATE8, NGATE4 \\
\hline
\end{tabular}

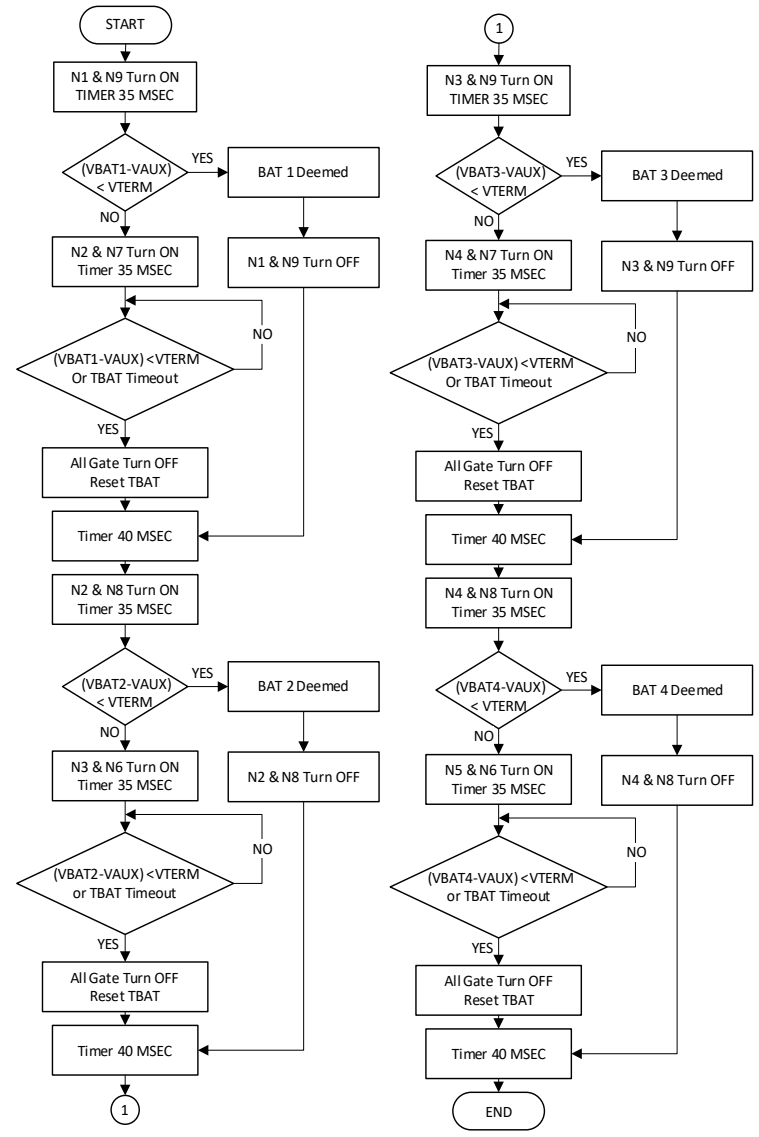

Figure 2. LTC3305 Timer Mode Operation Chart [6].

If the voltage differentiation is higher than chosen termination voltage, the top switch for the current state $\mathrm{N} 7$ and $\mathrm{N} 2$ are switched $\mathrm{ON}$, allowing the voltage of the battery 1 and auxiliary battery to be connected in parallel, that initiates the balancing process. And after $35 \mathrm{~ms}$ settled internal timer is passed up, the voltage comparator sensor starts to measure the voltage differentiation and compare it to the termination voltage [1], [6], [12].

Battery 1 will stay connected to the auxiliary battery until the voltage differentiation is on termination voltage range or TBAT timeout occurs. TBAT timeout is the time value for how long the balancing process is held for one battery on the stack. After the differentiation voltage achieve, the termination voltage values or TBAT timeout occurs, the top and bottom switch are both turned off and an internal timer is settled to $40 \mathrm{~ms}$ and after it passed the time, the process proceeds to the next battery, that is battery 2 [1], [6], [12].

The balancing process of each battery follow similar procedure. The detailed flow process of the LTC3305 timer mode operation is shown in Figure 2.

The balancing process of the continuous operation mode differs from the timer mode in terms of the continuation even if the battery voltage on the stack is balanced. The balancing process shut off only when the MODE pin is pulled to low, so the timer mode operation is selected [1], [2], [5], [6]

In the continuous mode operation, the balancing process is not terminated by a comparative sensor but 
terminated by TBAT timeout. It means that the auxiliary battery is always connected to the battery until TBAT timeout occurs, the voltage in the connected battery can change before it proceeds to the next battery. The voltage balancing result of this mode may be different from the programmed voltage termination. The worst scenario during the balancing process is first, when auxiliary battery voltage is far smaller than the voltage of the battery on the stack, and second, when the individual battery on stack voltage may be up to twice the value of the selected termination voltage [1], [5], [6].

Although the concept of balancing of the two modes has only slight differences, it has significant differentiation on the actual balancing process, the balancing process duration on the continuous mode is longer than timer mode because it also balanced the balanced battery [1], [6]. The detail of the continuous mode operation flow process is shown in Figure 3.

The LTC3305 voltage termination (VTERM), is the voltage differentiation between the auxiliary battery and the connected battery on the stack to be balanced. Termination voltage is settled using TERM1 and TERM2 pins on the integrated board [1], [6]. The pins configuration is shown in Table 2.

The battery is balanced if the voltage differentiation is in the termination voltage range. For example, when the termination pin, TERM 1 is 0 or switched OFF and the TERM2 is 1 or switched ON, the voltage differentiation should be $\pm 50 \mathrm{mV}$ to be considered as balanced [1], [6].

Other than mentioned before, LTC3305 also has some features including under-voltage (UV) \& overvoltage (OV) fault threshold. It is also equipped with several indicators that allow users to monitor which battery is being balanced. For the detail of this LTC3305 conjugation method please refer to its datasheet [1], [6].

TABLE 2

LTC3305 TERMINATION VOLTAGE [6].

\begin{tabular}{|c|c|c|}
\hline TERM 1 & TERM 2 & V $_{\text {TERMINATE }}$ \\
\hline 0 & 0 & $\pm 12.5 \mathrm{mV}$ \\
\hline 0 & 1 & $\pm 50 \mathrm{mV}$ \\
\hline 1 & 0 & $\pm 25 \mathrm{mV}$ \\
\hline 1 & 1 & $\pm 100 \mathrm{mV}$ \\
\hline
\end{tabular}

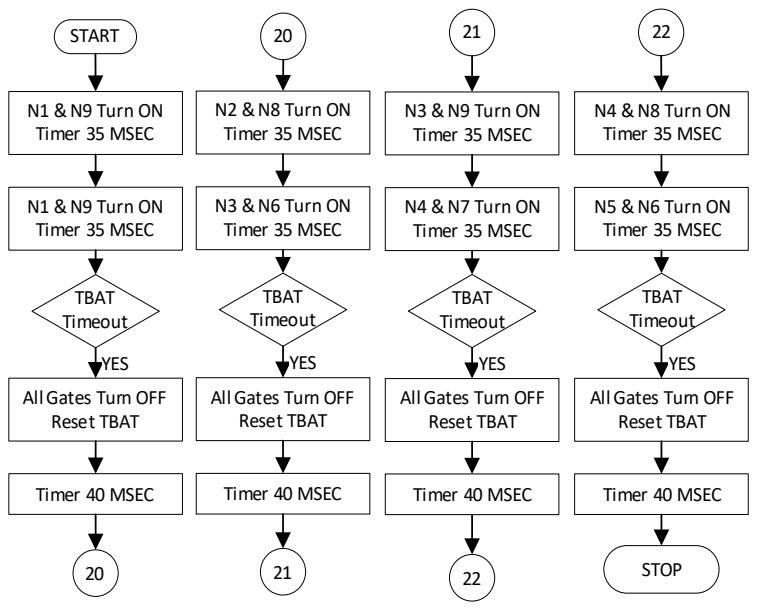

Figure 3. LTC3305 Continuous Mode Operation Chart [6].

\section{Implemented Concept}

The concept that has been implemented in this project is based on the LTC3305 balancing technique which balances four or more lead-acid batteries configured in a series configuration. This system employs an auxiliary battery to transfer excess charge from or to each connected battery in the stack. A metal oxide semiconductor field effect transistor (MOSFET) is also used to connect the battery on the stack to the auxiliary battery in the parallel mode so there is no limit of current flowing to or from the auxiliary battery [1], [4]-[12]. The MOSFET switch arrangement is illustrated in Figure 4.

The model of arranged switch consists of 9 gates as its switch and each gate has an important function to ensure the charge can move freely to or from the auxiliary battery to each battery on the stack. The gate is driven by Microcontroller NUCLEO-F767ZI with target controller STM32F767ZI from STMicroelectronics NV to ensure the switching gate is switched on at the correct time, correct duty cycle, and correct frequency [13].

The proposed parallelization approach is similar to LTC3305 which is shown in Table 1, that there are top and bottom switches arrangement for four batteries stack.

The top switch is the switch of arranged MOSFET which connects the positive side of the battery on the stack and the auxiliary battery. The bottom switch is the switch of arranged MOSFET which connects the negative side of the battery on the stack and the auxiliary battery.

\section{DESIGN AND IMPLEMENTATION}

\section{A. Proposed Balancing Method}

The proposed balancing method is by replacing the LTC3305 with a NUCLEO F767ZI as its main microcontroller. The working principle of this work is illustrated in proposed concept diagram in Figure 5.

Based on Figure 5, the proposed design has 8 blocks. In the input area, there are the auxiliary battery voltage sensor, battery stack voltage sensor, auxiliary battery current sensor, dipswitch for process and mode selector, and temperature sensor. In the output area, there are NGATE switches to control the MOSFET gate, LCD indicator, and NUCLEO F767ZI as the main microcontroller.

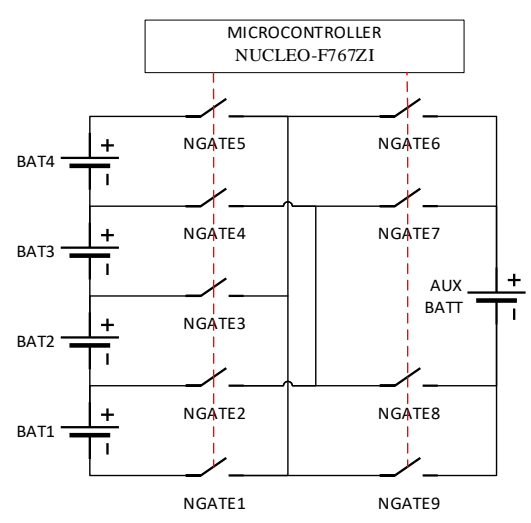

Figure 4. Cell Balancing Diagram with Parallelization Cell to Auxiliary Battery [1], [6]. 


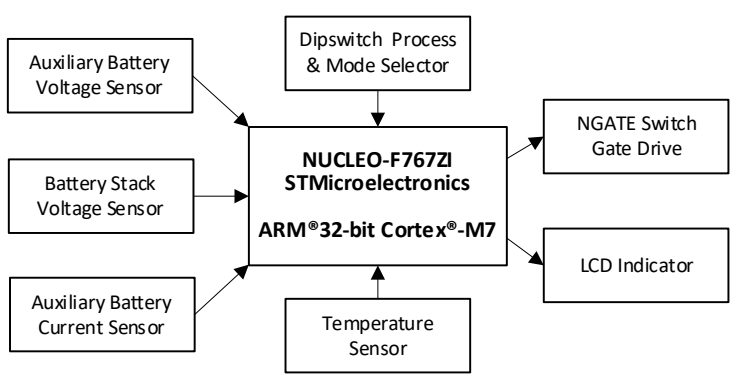

Figure 5. Proposed Concept Diagram.

\section{B. Working Principle of Each Block}

The lead-acid battery balancer system works by accessing many blocks operation, each block has different functionality and is made separately to prevent malfunction of its component.

\section{1) Battery Stack Resistive Voltage Sensor}

A battery stack resistive voltage sensor is used to measure each battery voltage using a resistive voltage sensor. The sensor generated variable voltage at $0-3.3$ Volt DC and then the analog voltage data was read by analog input on NUCLEO F767ZI before converting it to actual voltage value inside the microcontroller [14]. The circuit is shown in Figure 6.

The measuring system of this device is conducted by accumulating the voltage from the battery voltage below the measured battery. To measure each battery, measuring patterns as shown in Table 3 were used.

As shown in Table 3, to measure battery 2, battery 1 voltage and battery 2 ADC value are required. Similarly, it applies to batteries 3 and 4 which requires the voltage value of lower battery on stack before adding their ADC values.

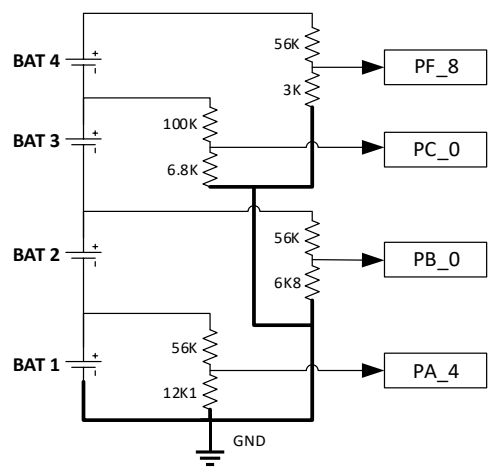

Figure 6. Battery Stack Resistive Voltage Sensor Diagram.

TABLE 3

BatTery Voltage MEasurement Way

\begin{tabular}{|c|c|c|c|c|}
\hline $\begin{array}{c}\text { Measured } \\
\text { Battery }\end{array}$ & \multicolumn{4}{|c|}{ Measuring Data } \\
\hline Battery 1 & $\begin{array}{c}\text { ADC } \\
\text { Value }\end{array}$ & - & - & - \\
\hline Battery 2 & $\begin{array}{c}\text { Battery 1 } \\
\text { Voltage }\end{array}$ & $\begin{array}{c}\text { ADC } \\
\text { Value }\end{array}$ & - & - \\
\hline Battery 3 & $\begin{array}{c}\text { Battery 1 } \\
\text { Voltage }\end{array}$ & $\begin{array}{c}\text { Battery 2 } \\
\text { Voltage }\end{array}$ & $\begin{array}{c}\text { ADC } \\
\text { Value }\end{array}$ & - \\
\hline Battery 4 & $\begin{array}{c}\text { Battery 1 } \\
\text { Voltage }\end{array}$ & $\begin{array}{c}\text { Battery 2 } \\
\text { Voltage }\end{array}$ & $\begin{array}{c}\text { Battery 3 } \\
\text { Voltage }\end{array}$ & $\begin{array}{c}\text { ADC } \\
\text { Value }\end{array}$ \\
\hline
\end{tabular}

The NUCLEO F767ZI analog reading range is from $0 \mathrm{~V}$ to $3.3 \mathrm{~V} \mathrm{DC}$, which means the resistor selection must follow the rule that the output of the resistive voltage sensor on maximum value does not exceed $3.3 \mathrm{~V}$. If the value exceeds this rule, the NUCLEO F767ZI can resist exploding, but the output digital read by the analog pin is at the maximum of $3.3 \mathrm{~V} \mathrm{[13],} \mathrm{[14].}$

\section{2) Auxiliary Battery Isolated Voltage Sensor}

An auxiliary battery isolated voltage sensor is an independent device used to measure the auxiliary battery voltage using a resistive voltage sensor system. The resistive voltage sensor also uses a voltage divider system and then generates analog data $0-5 \mathrm{~V}$ DC before converting it to certain value in the microcontroller [15].

Arduino Nano uses analog to digital converter on 10bit data to obtain high precision data at $0 \sim 1024$ data. The data is stored in decimal value and then translated to 10-bit of output [15]. The detailed circuit is shown in Figure 7.

From Figure 7, there are 10 pieces of optocoupler which represent the 10-bit of output from $2^{0}$ to $2^{9}$. To isolate the sensor from the main microcontroller, the optocouplers are used in this system. The 10 pieces of this optocoupler have their unique function and data value inside them, which are shown in Table 4.

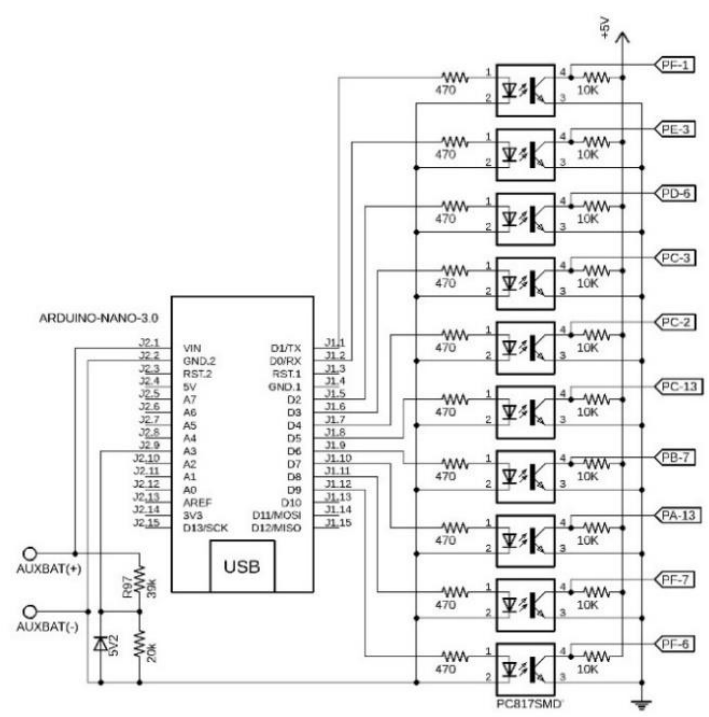

Figure 7. Auxiliary Battery Resistive Voltage Sensor Diagram

TABLE 4

OPTOCOUPLER OUTPUT VALUE

\begin{tabular}{|c|c|c|c|c|}
\hline No & $\begin{array}{c}\text { Arduino } \\
\text { Output Pin }\end{array}$ & $\begin{array}{c}\text { NUCLEO } \\
\text { Pin }\end{array}$ & Value & $\begin{array}{c}\text { Decimal } \\
\text { Value }\end{array}$ \\
\hline 1 & D0 & PE_3 & $2^{0}$ & 1 \\
\hline 2 & D1 & PF_1 & $2^{1}$ & 2 \\
\hline 3 & D2 & PD_6 & $2^{2}$ & 4 \\
\hline 4 & D3 & PC_3 & $2^{3}$ & 8 \\
\hline 5 & D4 & PC_2 & $2^{4}$ & 16 \\
\hline 6 & D5 & PC_13 & $2^{5}$ & 32 \\
\hline 7 & D6 & PB_7 & $2^{6}$ & 64 \\
\hline 8 & D7 & PA_13 & $2^{7}$ & 128 \\
\hline 9 & D8 & PF_7 & $2^{8}$ & 256 \\
\hline 10 & D9 & PF_6 & $2^{9}$ & 512 \\
\hline
\end{tabular}


TABLE 5

BINARY VALUE OF OPTOCOUPLER

\begin{tabular}{|c|c|c|c|c|c|c|c|c|c|c|c|}
\hline No & ADC & $2^{0}$ & $2^{1}$ & $2^{2}$ & $2^{3}$ & $2^{4}$ & $2^{5}$ & $2^{6}$ & $2^{7}$ & $2^{8}$ & $2^{9}$ \\
\hline 1 & 100 & & & घ & & & घ & घ & & & \\
\hline 2 & 600 & & & & घ & घ & & घ & & & घ \\
\hline 3 & 800 & & & & & & घ & & & घ & घ \\
\hline 4 & 1000 & & & & घ & & घ & घ & च & घ & घ \\
\hline
\end{tabular}

From Table 4, analog data reading by analog input pin in Arduino Nano is directly converted to a digital value using binary value [15]. Each pin has the value that is described in Table 5 .

Based on Table 5, when the analog data read by Arduino Nano is 100, the value of the bits that must be $\mathrm{ON}$ is $2^{2}, 2^{5}$, and $2^{6}$, others than these bits, it must be turned-off.

\section{3) Auxiliary Battery Current Sensor}

An auxiliary battery current sensor is used to measure drew current to or from the auxiliary battery to the battery on the stack. In addition to monitor the current, this system is also used for protection from overcurrent draw during the switching process. When the overcurrent occurs, the switching process has to open and the process stop, subsequently, causing error indicator to be lit. An auxiliary battery current sensor is a device based on ACS758 from Allegro Microsystems, the schematic is shown in Figure 8.

The used sensor type is ACS758LCB-050B-PFF-T, which can sense a current flowing through it in a bidirectional way, with a sensing sensitivity of $40 \mathrm{mV} / \mathrm{A}$ with maximum sensing of $50 \mathrm{~A}$ [16], [17].

\section{4) Temperature Sensor}

LM35-based temperature sensor is an integrated circuit device to measure temperature in the surrounding area of the sensor. The LM35 series are precise integrated-circuit temperature sensor devices with an analog voltage output linearly proportional to the centigrade temperature, it is a low-cost temperature sensor due to wafer lever trimming and is able to sense a minimum of $-55^{\circ} \mathrm{C}$ to a maximum of $150{ }^{\circ} \mathrm{C}$ [18]. The schematic detail is shown in Figure 9.

The output is an analog voltage ranging from -550 $\mathrm{mV}$ to $1500 \mathrm{mV}$, even the output voltage is very low, the microcontroller is still able to obtain accurate data from the sensor. The sensor sensitivity is about $0+10.0 \mathrm{mV} /{ }^{\circ} \mathrm{C}$ with voltage output for different temperature is listed in Table 6 [18].

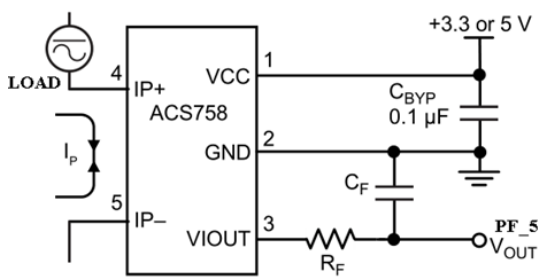

Figure 8. Auxiliary Battery Current Sensor Diagram [16].

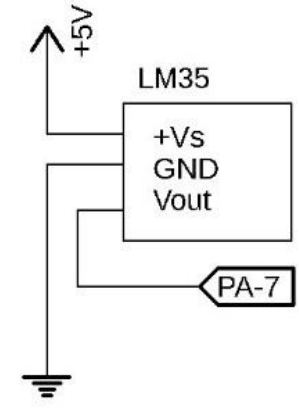

Figure 9. LM 35 Temperature Sensor Diagram [18].

TABLE 6

LM35 TEMPERATURE VS VOLTAGE [18]

\begin{tabular}{|c|c|}
\hline Temperature $\left({ }^{\circ} \mathbf{C}\right)$ & Voltage Output $(\mathbf{m V})$ \\
\hline 150 & 1500 \\
\hline 25 & 250 \\
\hline-55 & -550 \\
\hline 30 & 300 \\
\hline 100 & 1000 \\
\hline
\end{tabular}

Based on Table 6, when the voltage output of the sensor is $1000 \mathrm{mV}$, the temperature is read as $100^{\circ} \mathrm{C}$. this value is obtained by division of the voltage output and the sensor sensing ability $\left(0+10.0 \mathrm{mV} /{ }^{\circ} \mathrm{C}\right)$.

\section{5) Dipswitch Process Selector}

Dipswitch process selector is a device used to select the operational mode of this battery balancer system. The schematic is shown in Figure 10.

From Figure 10, this device consists of 2 pieces 10 $\mathrm{K} \Omega$ and 1 piece of 2 pin dipswitch, which each position of the dipswitch ON or OFF has a value inside it. The details are shown in Table 7.

Based on Table 7, to enter the timer mode, the dipswitch pole 1 and pole 2 must be OFF, to enter the continuous mode, the dipswitch pole 1 must be $\mathrm{ON}$ and pole 2 must be OFF.

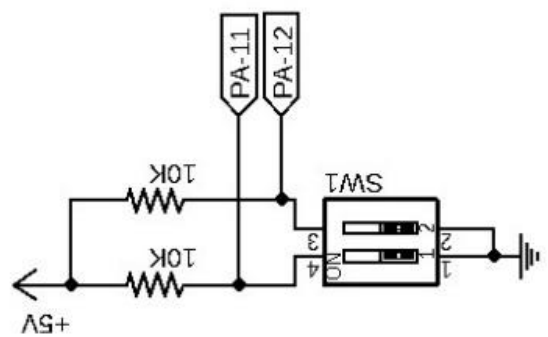

Figure 10. Dipswitch Process Selector Diagram.

TABLE 7

DiPSWITCH PROCESS SELECTOR POLE POSITION ARRANGEMENT

\begin{tabular}{|c|c|c|}
\hline POLE 1 & POLE 2 & REMARKS \\
\hline OFF & OFF & Timer Mode \\
\hline ON & OFF & Continuous Mode \\
\hline OFF & ON & Batch Test Mode \\
\hline ON & ON & Individual Test Mode \\
\hline
\end{tabular}




\section{6) Dipswitch Test Pin Selector}

Dipswitch test pin selector works only when the control system enters the batch test mode or individual test mode. The circuit design is shown in Figure 11.

Batch test mode is designed to check the device performance of energy transfer unit with the actual balancing process of each battery on the battery stack. The pin arrangement is shown in Table 8.

Based on Table 8 , each pin has a decided function. Pole 1 is for battery 1 batch test, pole 2 for battery 2, pole 3 for battery 3 , and pole 4 is for battery 4 batch test. For battery 1 , when pole 1 is ON, gates $7,2,9$, and 1 will be $\mathrm{ON}$ and connect the battery 1 and auxiliary battery.

Individual test mode designed to activate one by one of a pulse width modulation (PWM) gate on energy transfer unit, this mode programmed using bit function which each pole has unique value on it, for a further explanation please refer to Table 9 .

Based on Table 9, each bit or pole has a decided value, for example, pole 3 has $2^{2}$ or equal to 4 . On certain conditions, activating the PWM pin not only requires a single pole to be activated but also possible to require three poles, for a further explanation, refer to Table 10 .

Based on Table 10, during the individual test operation, for activating NGATE 5 , the pole 3 and pole 1 must be activated. This applies to other NGATE as well, each pole must be activated following Table 10 for each of the NGATE activation poles.

The concept of this data reading is similar to an isolated voltage sensor for auxiliary battery which also reads the data based on bit function. When the pole switch has been selected the NUCLEO pin generates PWM until the pole is switched OFF or going to another NGATE switch.

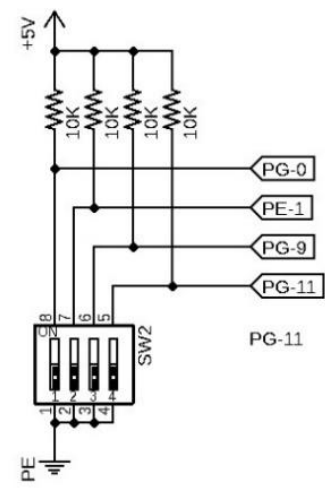

Figure 11. Dipswitch Test Pin Selector Diagram.

TABLE 8

Batch Test Mode Pole ARRANGEMENT

\begin{tabular}{|l|l|l|l|}
\hline Pole & $\begin{array}{l}\text { NUCLEO } \\
\text { Pin }\end{array}$ & Function & Activated Gate \\
\hline 1 & PG_0 & $\begin{array}{l}\text { Battery 1 Gate Batch } \\
\text { Test }\end{array}$ & $\begin{array}{l}\text { Gate 7, Gate 2, Gate } \\
\text { 9, Gate 1 }\end{array}$ \\
\hline 2 & PE_1 & $\begin{array}{l}\text { Battery 2 Gate Batch } \\
\text { Test }\end{array}$ & $\begin{array}{l}\text { Gate 6, Gate 3, Gate } \\
\text { 8, Gate 2 }\end{array}$ \\
\hline 3 & PG_9 & $\begin{array}{l}\text { Battery 3 Gate Batch } \\
\text { Test }\end{array}$ & $\begin{array}{l}\text { Gate 7, Gate 4, Gate } \\
\text { 9, Gate 3 }\end{array}$ \\
\hline 4 & PG_11 & $\begin{array}{l}\text { Battery 4 Gate Batch } \\
\text { Test }\end{array}$ & $\begin{array}{l}\text { Gate 6, Gate 5, Gate } \\
8, \text { Gate 4 }\end{array}$ \\
\hline
\end{tabular}

TABLE 9

INDIVIDUAL TEST MODE POLE ARRANGEMENT

\begin{tabular}{|c|c|c|c|}
\hline Pole & NUCLEO Pin & Value & Decimal Value \\
\hline 1 & PG_0 & $2^{0}$ & 1 \\
\hline 2 & PE_1 & $2^{1}$ & 2 \\
\hline 3 & PG_9 & $2^{2}$ & 4 \\
\hline 4 & PG_11 & $2^{3}$ & 8 \\
\hline
\end{tabular}

\section{7) NUCLEO F767ZI Microcontroller}

To maintain and control all connected equipment, the NUCLEO F767ZI is selected. Figure 12 shows NUCLEO F767ZI is a high speed and high-performance microcontroller from STMicroelectronics which its core is based on an ARM® chipset on 32-bit Cortex ${ }^{\circledR}-\mathrm{M} 7$ running up to $216 \mathrm{MHz}$, this device is a family of STM32 144 board which provides a flexible and affordable way for users to try out new programming concepts and build a prototype with the STM32 microcontroller [13].

TABLE 10

INDIVIDUAL TEST Mode Gate SwITCH

\begin{tabular}{|c|c|c|}
\hline $\begin{array}{c}\text { NGATE } \\
\text { Switch to be } \\
\text { Activate }\end{array}$ & Activated Pole & NUCLEO Pin \\
\hline 1 & 1 & PG_0 \\
\hline 2 & 2 & PE_1 \\
\hline 3 & 2,1 & PE_1, PG_0 \\
\hline 4 & 3 & PG_9 \\
\hline 5 & 3,1 & PG_9, PG_0 \\
\hline 6 & 3,2 & PG_9, PE_1 \\
\hline 7 & $3,2,1$ & PG_9, PE_1, PG_0 \\
\hline 8 & 4 & PG_11 \\
\hline 9 & 4,1 & PG_11, PG_0 \\
\hline
\end{tabular}

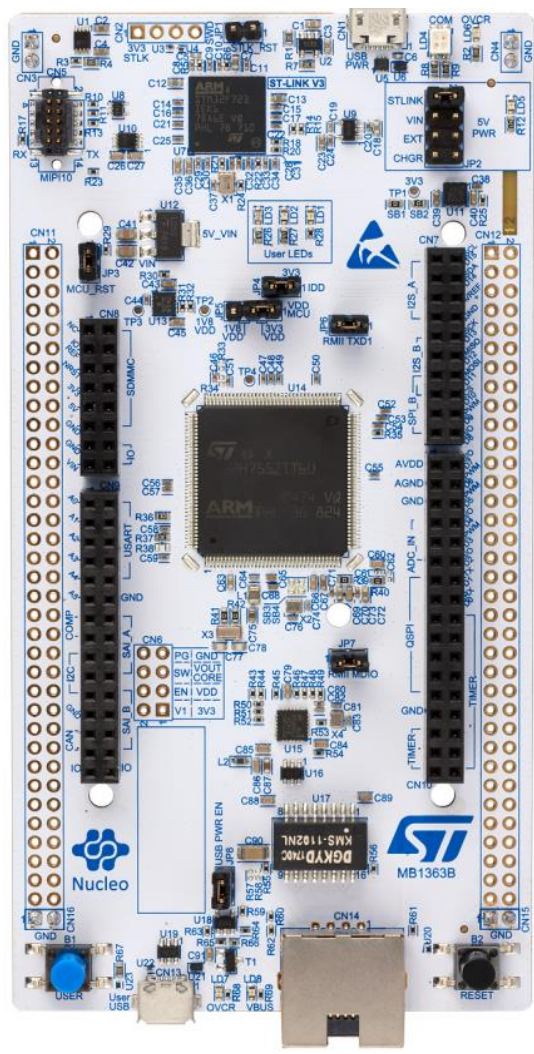

Figure 12. NUCLEO F767ZI [13]. 
The requirement of this system needs at least $40 \mathrm{I} / \mathrm{O}$ points which can be freely used without any restriction from an internal setting of the microcontroller board itself. NUCLEO F767ZI provides 144 I/O point which is sufficient to use for this system. Even there is a restriction, restriction can be avoided by using other ports. Additionally, other microcontroller boards scarcely satisfy the requirement of 10 ports of high-speed PWM output.

\section{8) Power Supply Unit}

The power supply unit is a simple device used to regulate the battery voltage on $12 \mathrm{VDC}$ to $5 \mathrm{VDC}$ and directly connect the output to the power supply $+5 \mathrm{~V}$ on the NUCLEO board. This device is used to power all devices which use 5VDC as their power supply [19], [20]. The circuit of this device is shown in Figure 13.

Based on Figure 13, this device consists of two 100 $\mu \mathrm{F}$ capacitors as filters to stabilize the output and single voltage regulator IC 7805 from Texas Instrument [19], [20].

\section{9) LCD Monitor}

LCD Monitor is the main device for displaying the status of the battery balancer system. It is displayed voltages of batteries stack, auxiliary battery voltage, auxiliary battery current, surrounding temperature, and which battery is being balanced [19], [20]. This device consists of LCD 2004 and its supporting circuit. Its circuit is shown in Figure 14.

The $20 \mathrm{k} \Omega$ of potentiometer shown in Figure 14 above is used for adjusting the brightness of the display unit and the $1 \mathrm{~K} 2$ resistor is used to illuminate the internal LED in the display unit.

\section{0) Energy Transfer Unit}

Energy transfer units are electronic relay devices that is used to transfer energy to or from the battery stack to

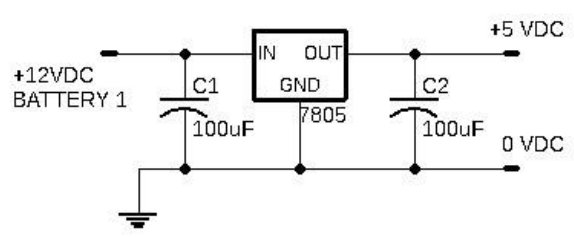

Figure 13. DC 5Volt Power Supply Diagram.

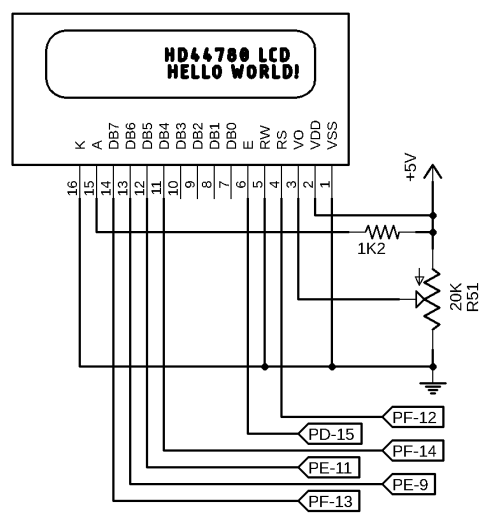

Figure 14. LCD 1602 Diagram. the auxiliary battery when there is voltage differentiation between them to keep the battery voltage in balance.

The detailed schematic is shown in Figure 15. The connection uses a DC-DC converter as an isolated power supply to activate the bidirectional switch of MOSFET [21]. Also, an HCPL 3120 optocoupler is used to separate the voltage between the microcontroller and the MOSFET switch. The schematic in Figure 15 is shown as a single energy transfer unit, which means there are 9 copied schematics to replace the NGATE switch shown in Figure 4 implemented concept.

The PWM pin on the NUCLEO F767ZI board to be connected to PWM IN is designed as shown in Table 11. The assigned pin for each NGATE is as follows; for NGATE 3, the PWM pin is PC_7 on the NUCLEO F767ZI and this is also applied for another NGATE.

\section{Battery Balancer Working System}

The lead-acid battery balancing system utilized fourmode, two modes are based on LTC 3305, and other two modes are additional modes for an easier way to check and troubleshoot the circuit [1], [6]. The workflow of the battery balance is available in Figure 16.

As shown in Figure 16, after the microcontroller reads the parameter, the system starts to read the operation mode. Following Table 7, to enter each mode, pole of each dipswitch needs to be modified.

There are four points where the program loop will begin on the sequencer, timer mode operation, continuous mode operation, batch test mode and the last is individual test mode. Each mode has its sequence with its unique function. Further explanations for each mode are discussed in following subsections, and extended discussion is available in [1], [6].

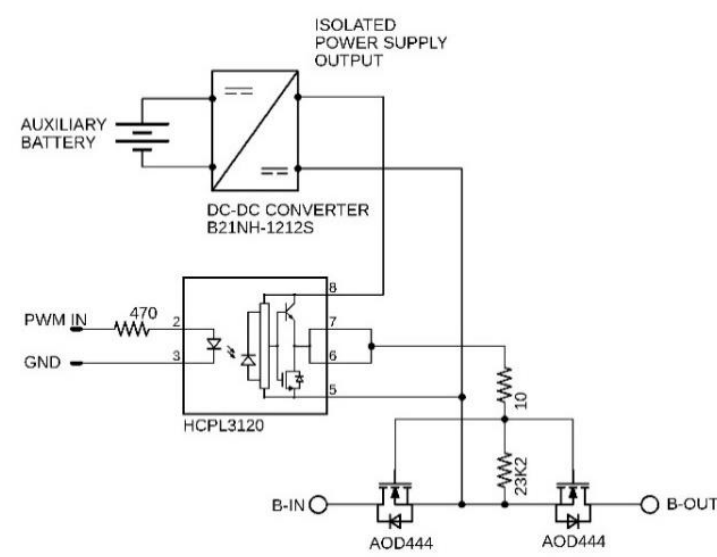

Figure 15. Energy Transfer Unit Sectional Diagram.

TABLE 11

PWM PIN FOR ENERGY TRANSFER UNIT

\begin{tabular}{|c|c|}
\hline NGATE Number & PWM Pin \\
\hline NGATE 1 & PA_5 \\
\hline NGATE 2 & PB_6 \\
\hline NGATE 3 & PC_7 \\
\hline NGATE 4 & PB_10 \\
\hline NGATE 5 & PB_4 \\
\hline NGATE 6 & PA_3 \\
\hline NGATE 7 & PD_13 \\
\hline NGATE 8 & PE_14 \\
\hline NGATE 9 & PE_13 \\
\hline
\end{tabular}




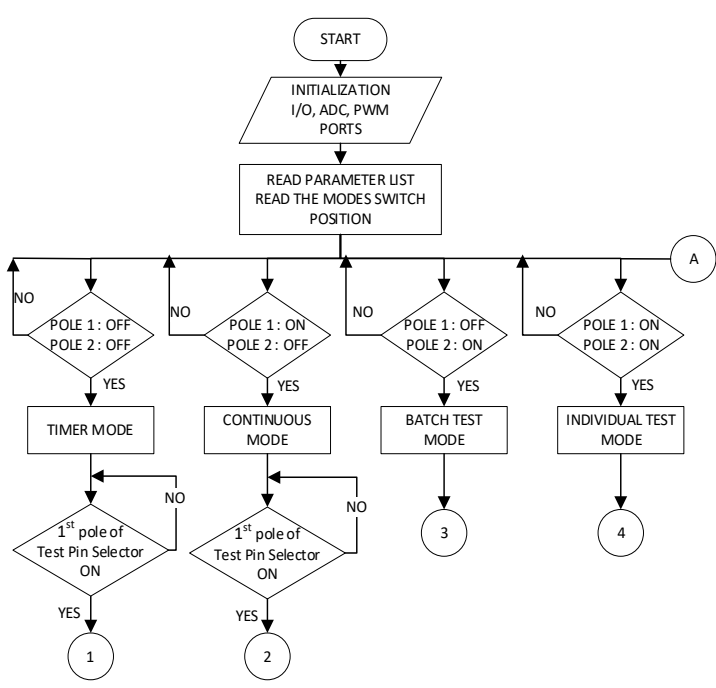

Figure 16. Head Flow Battery Balancer Working System Chart.

To enable the modes, users must change the pole position of the dipswitch process selector following the data presented in Table 7.

Timer mode operation is a mode based on LTC3305 which the balancing process depends on sensor and timeout value. The balancing method of timer mode operation is the same as shown in Figure 2, which the balancing process run continuously from battery 1 till battery 4 on stack repeatedly [1], [6]

The balancing process of this method explained as follows: battery 1 will end if the sensor of battery voltage determine that the voltage differentiation is in the accepted range or the timeout value has been achieved, then the balancing process proceeds to the next battery, in this case, battery 2 , and the process repeats until the voltage of the battery on the stack and auxiliary battery has been balanced.[1], [6].

\section{1) Continuous Mode Operation}

Continuous mode operation is a mode based on LTC3305 in which the balancing method depends on the timeout setting value. The balancing process follows similar procedure as shown in Figure 3, that run continuously from battery 1 till battery 4 on stack repeatedly [1], [6].

The balancing process of this method proceeds as for follows, battery 1 will end if the timeout value has been achieved, then the balancing process continue to the next battery, in this case, battery 2 , and the process repeats until the voltage of the battery on the stack and auxiliary battery has been balanced [1], [6].

\section{2) Batch Test Mode}

Batch test mode is a menu for driving the battery balancer system by connecting the top and bottom switch of the auxiliary battery to a single battery on stack continuously while the switch is switched ON. This mode is used to test the balancing process of the single battery on stack one by one to determine whether the battery is in perfect condition or bad condition, this mode is created because while the system working on continuous mode operation or timer mode operation, it is difficult to check which circuit needs to be maintained because its switch is switched ON just for a while, while the batch-test mode is always running balancing process on a single battery on the stack during the dipswitch switched ON [1], [6]. The detail is shown in Figure 17. As shown in Figure 17, to enter the battery batch-test mode, each pole must be settled correctly according to Table 8 .

\section{3) Individual Test Mode}

Individual test mode is a menu for driving the battery balancer system one from nine energy transfer units continuously during the switch is switched ON. This mode is used to test the balancing process on single energy transfer units one by one to evaluate whether they are working properly or not. The detailed process of this model is shown in Figure 18.

As shown in Figure 18, to activate individual battery test mode, each pole must be settled correctly according to Table 10 . The individual test mode drives only a single energy transfer unit at a time, in comparison of four energy transfer units in the batch test mode [1], [6].

\section{RESUlt AND DiscuSSION}

\section{A. General Result}

The general result of this experiment is all the connected block components work properly. The connected block consists of a resistive voltage sensor for the battery stack, an isolated voltage sensor for auxiliary battery, an auxiliary battery current sensor, a temperature sensor, a dipswitch process selector, a dipswitch test pin selector, a NUCLEO F767Zi microcontroller, a power supply circuit, an LCD Monitor, and an energy transfer unit.

\section{B. Individual Test Mode Operation Result}

Individual test mode is a mode specifically designed for testing and confirming each of the energy transfer unit blocks work properly before attaching it to the fully connected system. When the abnormality is detected, the energy transfer unit must be repaired or replaced with a spare energy transfer unit.

The internal microcontroller parameter to drive the energy transfer unit is divided into 3 data parameters as shown in Table 12.

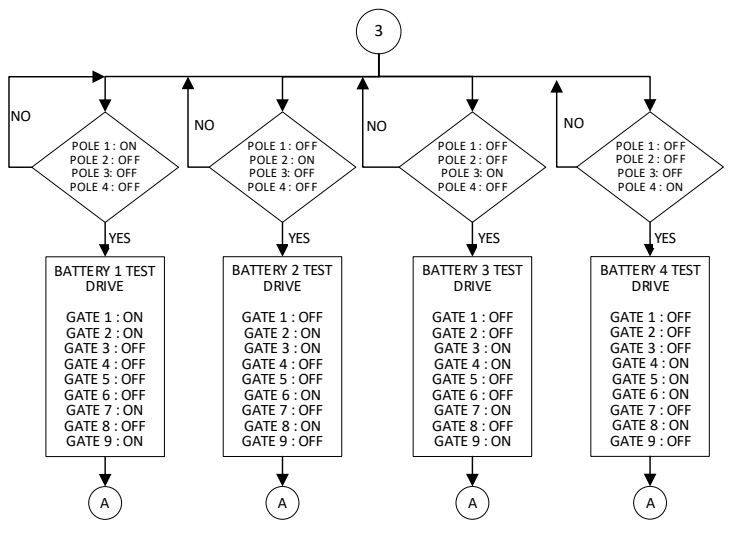

Figure 17. Batch Test Mode Operation Chart 


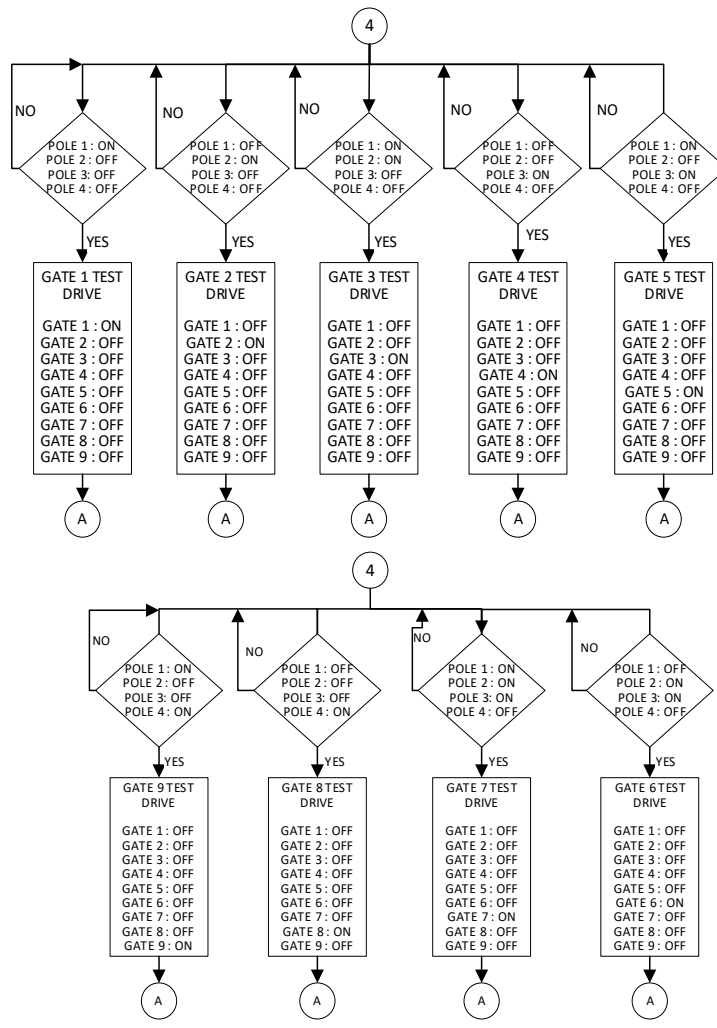

Figure 18. Individual Test Mode Operation Chart

The experiment was conducted twice, the first was when the energy transfer unit was on the positive side of the battery, and the second was when the energy transfer unit was placed on the negative side of the battery. Details of the first experiment circuit configuration is shown in Figure 19. Single Energy Transfer Unit on Battery Positive Side Test Result

Figure 20 displays the result in the energy transfer unit when the PWM is charged with specification listed in Table 12. The result of the positive side test of the energy transfer unit shown in Figure 20 is satisfactory, the wave frequency and duty cycle are nearly identical to the expected base parameters shown in Table 12. Figure 22 displays the result in the energy transfer unit of the second experiment when the PWM is charged with specification listed in Table 12.

TABLE 12

INDIVIDUAL TEST MODE PARAMETER LIST

\begin{tabular}{|c|c|}
\hline DATA & VALUES \\
\hline Frequency of PWM & $10 \mathrm{kHz}$ \\
\hline Duty cycle of PWM & $80 \%$ \\
\hline Battery voltage (RMS) & $12.9 \mathrm{Volt}$ \\
\hline
\end{tabular}

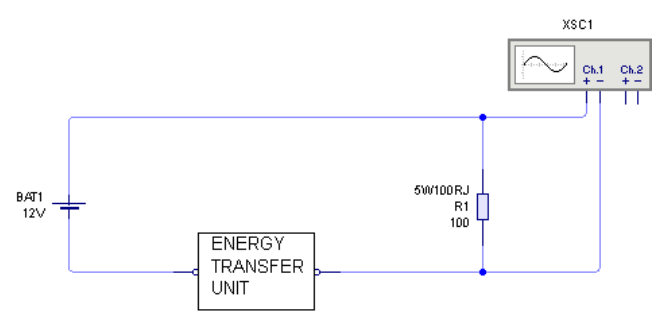

Figure 19. Single Energy Transfer Unit on Battery Negative Side Test Configuration.

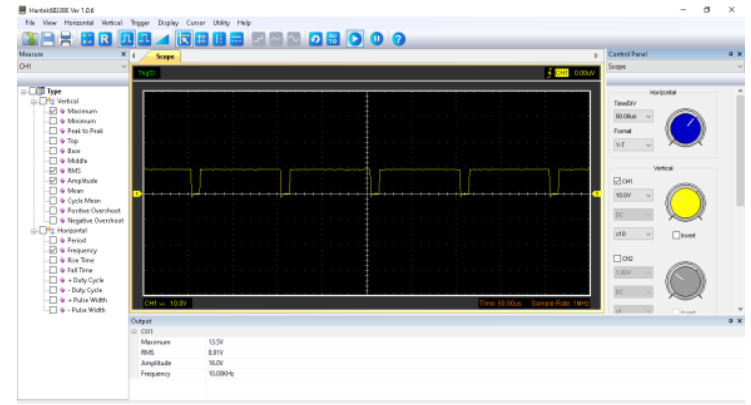

Figure 20. Single Energy Transfer Unit on Battery Positive Side Test Result.

The circuit configuration of the second experiment is shown in Figure 21, where the energy transfer unit is placed on the negative side of the battery.

As shown in Figure 22, the result is acceptable, although the waveform is not formed when there is no PWM to the energy transfer unit, there is no voltage on the resistor side. In the two experiments when the energy transfer unit is placed on the positive or negative side of the battery, the resistor temperature arises which indicates that the current flow through the circuit is AC.

\section{Batch Test Mode Operation Result}

Batch test mode is a mode specifically designed for testing and conforming whether one block of the energy transfer unit which consist of four energy transfer units works properly or not. This operational test can be done after passing the individual test.

The circuit diagram used to test the four energy transfer units is demonstrated in Figure 23 with a $120 \Omega$, $5 \mathrm{~W}$ resistor as a load.

While driving PWM on the circuit, the result on the load area is shown in Figure 24. Based on the result in Figure 24, the result of this batch test mode is satisfactory. In this experiment, the resistor temperature increased along the time.

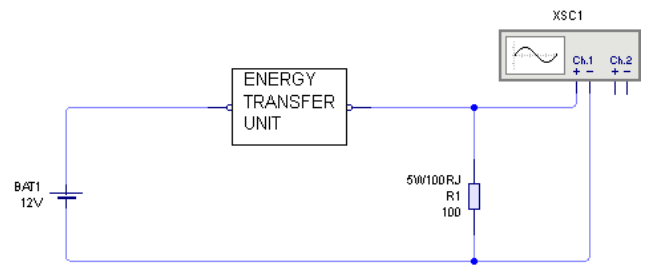

Figure 21. Single Energy Transfer Unit on Battery Positive Side Test Configuration.

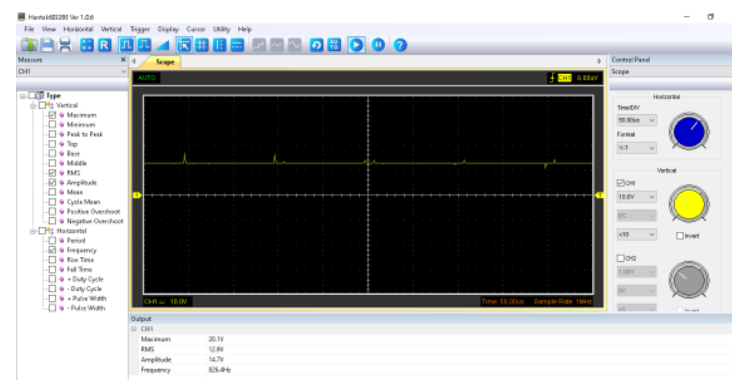

Figure 22. Single Energy Transfer Unit on Battery Negative Side Test Result. 


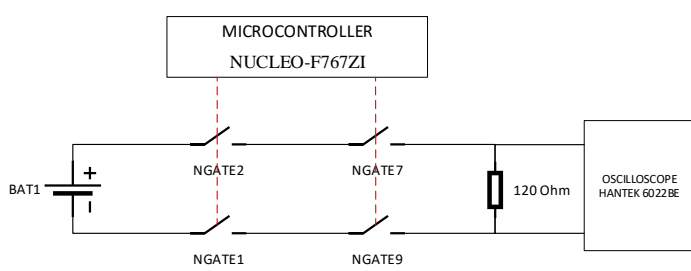

Figure 23. Batch Test Energy Transfer Unit Configuration.

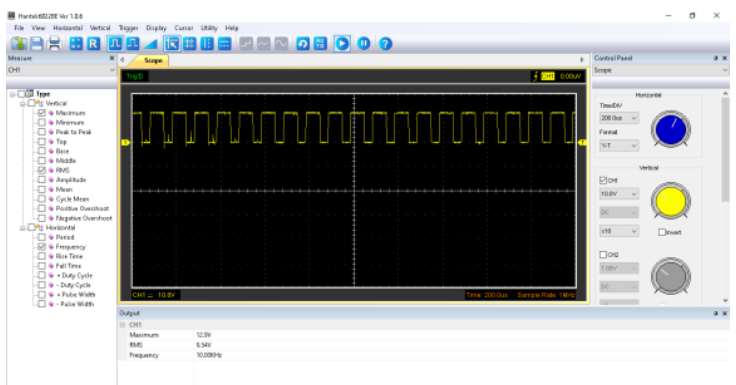

Figure 24. Batch Energy Transfer Unit Test Result.

\section{Timer Mode and Continuous Mode Testing Parameter}

The general parameter of a fully arranged energy transfer unit has two important points, PWM signal from the microcontroller to drive energy transfer unit and the time spent for the battery balancing process. Programmed parameters for PWM are shown in Table 13.

The NUCLEO F767ZI as the microcontroller used in this system is equipped with $216 \mathrm{MHz}$ maximum CPU frequency for high-speed data reading and processing. The internal parameter setting of the switching time or the duration of battery balancing process on a single battery on stack through an auxiliary battery is shown in Table 15. Down switch to top switch buffer time is a time gap between before driving the top switch of configured energy transfer unit and after driving the down switch of the configured energy transfer unit.

The voltage measurement result of each battery shown in Figure 25 until Figure 28 were taken after four batteries balancing process was completed or when the battery was on its steady condition, not during the balancing process is in progress. In these figures, y-axes represent the battery voltage in $\mathrm{mV}$ and $\mathrm{x}$-axes represent discrete-time step in minutes.

TABLE 13

PWM MICROCONTROLLER SPECIFICATION

\begin{tabular}{|c|c|c|c|c|}
\hline \multirow{2}{*}{$\begin{array}{c}\text { Gate } \\
\text { No. }\end{array}$} & \multicolumn{2}{|c|}{ BMS Program } & \multicolumn{2}{c|}{$\begin{array}{c}\text { Measured by } \\
\text { Oscilloscope }\end{array}$} \\
\cline { 2 - 5 } & Freq. & Duty cycle & Freq. & Duty cycle \\
\hline 1 & $100 \mathrm{~Hz}$ & $80 \%$ & $100 \mathrm{~Hz}$ & $80 \%$ \\
\hline 2 & $100 \mathrm{~Hz}$ & $80 \%$ & $100 \mathrm{~Hz}$ & $80 \%$ \\
\hline 3 & $100 \mathrm{~Hz}$ & $80 \%$ & $100 \mathrm{~Hz}$ & $80 \%$ \\
\hline 4 & $100 \mathrm{~Hz}$ & $80 \%$ & $100 \mathrm{~Hz}$ & $80 \%$ \\
\hline 5 & $100 \mathrm{~Hz}$ & $80 \%$ & $100 \mathrm{~Hz}$ & $80 \%$ \\
\hline 6 & $100 \mathrm{~Hz}$ & $80 \%$ & $100 \mathrm{~Hz}$ & $80 \%$ \\
\hline 7 & $100 \mathrm{~Hz}$ & $80 \%$ & $100 \mathrm{~Hz}$ & $80 \%$ \\
\hline 8 & $100 \mathrm{~Hz}$ & $80 \%$ & $100 \mathrm{~Hz}$ & $80 \%$ \\
\hline 9 & $100 \mathrm{~Hz}$ & $80 \%$ & $100 \mathrm{~Hz}$ & $80 \%$ \\
\hline
\end{tabular}

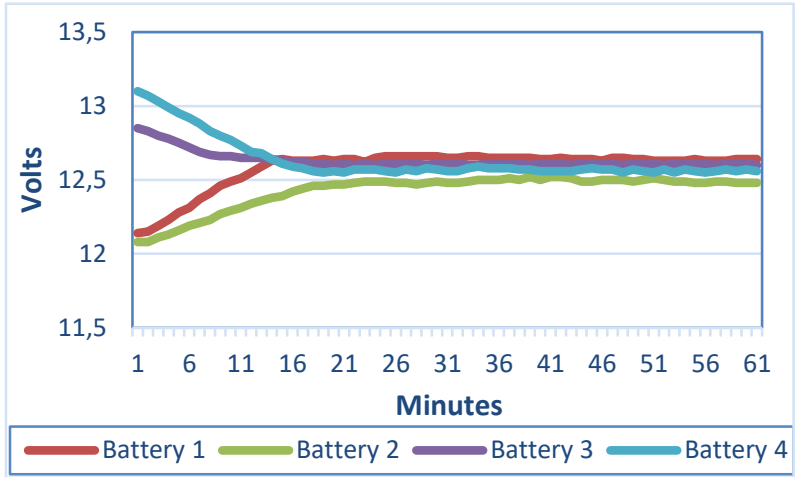

Figure 25. Timer Mode Test 1 Result.

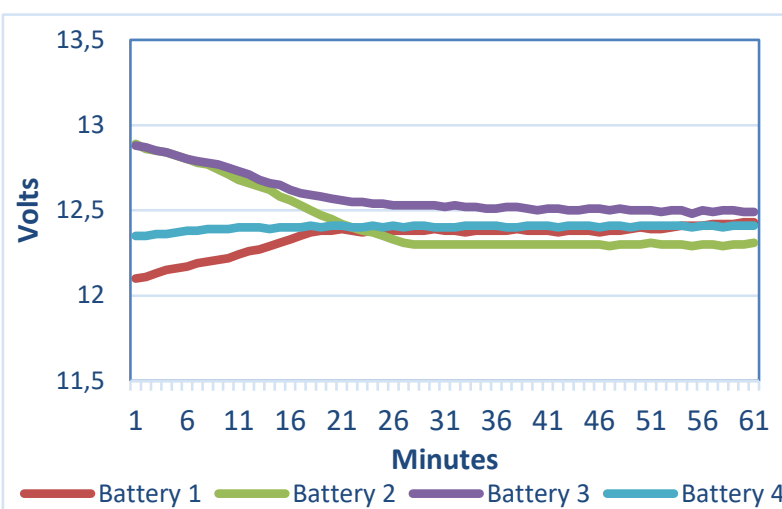

Figure 26. Timer Mode Test 2 Result.

\section{E. Timer Mode Operation Result and Analysis}

Timer mode operation is a mode based on LTC3305 which the balancing process depends on sensor and timeout value. The balancing method of timer mode operation is shown in Figure 2, that the balancing process run continuously from battery 1 until battery 4 on stack repeatedly.

The data result shown in Figure 25 and Figure 26 are voltage measurement of each battery on the stack. The experiment has been conducted twice with different initial battery voltage before the balancing process. The fully arranged energy transfer unit timer mode operation test 1 result is shown in Figure 25.

Based on the graph in Figure 25, the largest voltage differentiation in the last minute of the test is between battery 1 and battery 2 with the voltage imbalance of 160 $\mathrm{mV}$. The fully arranged energy transfer unit timer mode operation test 2 result is shown in Figure 26.

Compared to the chart of the test 1 in Figure 25, The results shown in Figure 26 is more stable. The largest voltage differentiation in the last minute of the test is also between battery 1 and battery 2 with the voltage imbalance of $180 \mathrm{mV}$.

TABLE 14

INTERNAL MICROCONTROLLER PARAMETER

\begin{tabular}{|l|l|l|}
\hline No & \multicolumn{1}{|c|}{ Setting Name } & \multicolumn{1}{c|}{ Value } \\
\hline 1 & TBAT Timeout & 5000 milliseconds \\
\hline 2 & $\begin{array}{l}\text { Down Switch to Top Switch Buffer } \\
\text { time }\end{array}$ & 35 milliseconds \\
\hline 3 & Next Battery Time Gap & 40 milliseconds \\
\hline
\end{tabular}


The battery balancing process in this work did not fully work, the battery voltage differentiation is over the voltage imbalance value of $12.5 \mathrm{mV}$. Despite the longer time applied during the experiment, the value of the battery voltage was unable to achieve the voltage imbalance below $12.5 \mathrm{mV}$. However, the battery balancing process was run properly without any overcurrent or overtemperature.

\section{F. Continuous Mode Operation Result and Analysis}

Continuous mode operation is a mode based on LTC3305 in which the balancing method depends on the timeout setting value. The balancing process is similar to process as shown in Figure 3 which the balancing process run continuously from battery 1 till battery 4 on stack repeatedly.

The data presented in Figure 27 and Figure 28 is the voltage measurement of each battery on the stack in continuous mode operation. The experiment has been conducted twice with different initial battery voltage before the balancing process. The full arranged energy transfer unit continuous mode operation test 1 result is shown in Figure 27.

Based on result charts in figure 27 result 1 for the continuous mode operation, the largest voltage differentiation in the last minute of the test is between battery 1 and battery 2 with the voltage imbalance of 170 $\mathrm{mV}$. The full arranged energy transfer unit continuous mode operation test 2 result is shown in Figure 28.

Based on result charts in Figure 28 result 1, the largest voltage differentiation in the last minute of the test is also between battery 1 and battery 2 with the voltage imbalance of $170 \mathrm{mV}$.

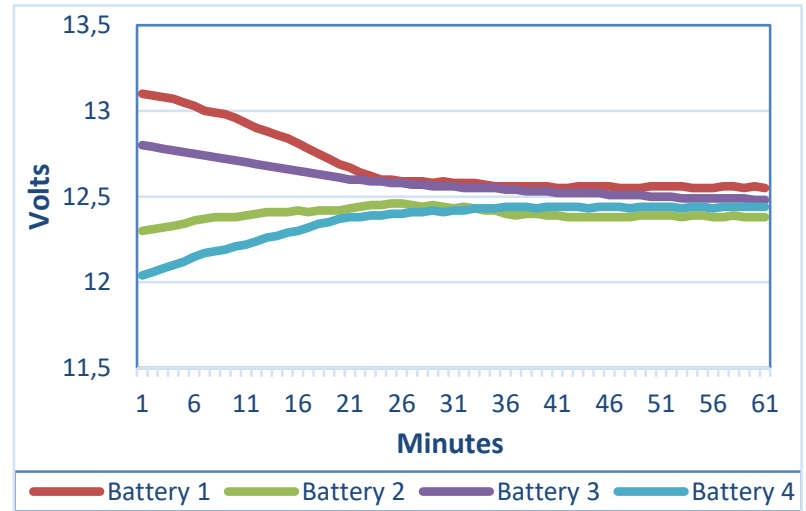

Figure 27. Continuous Mode Test 1 Result

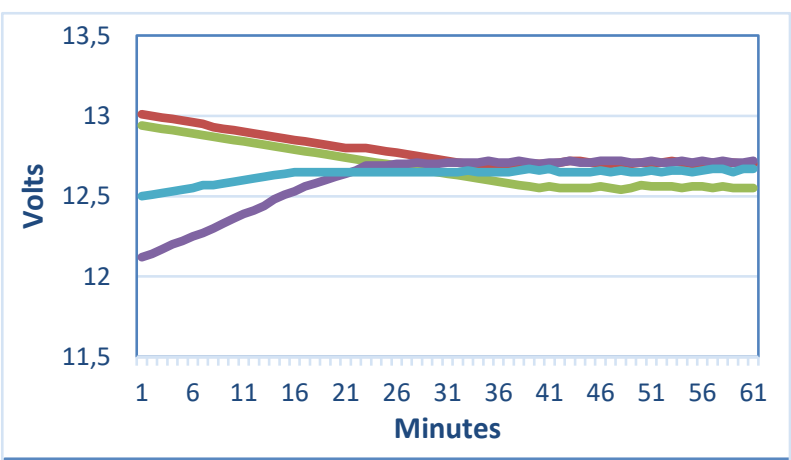

$\longrightarrow$ Battery 12 Battery $2 \rightleftharpoons$ Battery $3 \rightleftharpoons$ Battery 4

Figure 28. Continuous Mode Test 2 Result
Similar to the result in the timer mode, despite the longer time applied during the experiment, the value of the battery voltage was unable to achieve the voltage imbalance below $12.5 \mathrm{mV}$. However, the battery balancing process was run properly without any overcurrent and overtemperature.

\section{CONCLUSIONS}

The prototype of a microcontroller-based lead-acid battery balancing system for electrical vehicle application has been fabricated successfully. The actual batteries voltage monitoring with actual auxiliary battery current drawn monitoring have been attached to the system. Also, an additional testing mode for an easier way to check the output on each transfer unit has been added. Lastly, the overcurrent and overheat protection system of this device has been successfully built.

Based on the results of the testing analysis, the largest voltage imbalance is between battery 1 and battery 2 . In timer mode test 2 of the balancing system, the obtained voltage imbalance is $180 \mathrm{mV}$, which is higher than the target of voltage imbalance that to be below $12.5 \mathrm{mV}$.

The balancing process for the timer mode operation is faster 1.5 times than for the continuous mode operation. In addition, the timer mode also has larger voltage imbalance compared to the continuous mode. Lastly, there were no overcurrent and overtemperature observed during the balancing process for both timer mode and continuous mode operation.

\section{ACKNOWLEDGMENTS}

The authors are grateful to Dr. Irwan Purnama (LIPI) for his valuable guidance and discussion throughout the research process. Also, authors are grateful to the Research Institute and Community Service (RICS) of President University for supporting the publication work.

\section{REFERENCES}

[1] D. Setiawan, N. A. Mahardiono, and I. Purnama, "A time improvement technique of lead-acid battery balancing system," in Proceedings of the 2nd International Conference on Automation, Cognitive Science, Optics, Micro ElectroMechanical System, and Information Technology, ICACOMIT 2017, Jakarta, 2017

[2] D. A. Asfani et al., "Electric Vehicle Research in Indonesia: A Road map, Road tests, and Research Challenges," IEEE Electrification Magazine, vol. 8, no. 2, pp. 44-51, Jun. 2020. J. Raharjo, A. Wikarta, I. Sidharta, M. N. Yuniarto, M. I. Firdaus, and M. F. B. Zulhaimi, "Environmental testing for reliable battery management system in electric vehicle," Journal of Physics: Conference Series, vol. 1517, no. 1, p. 012025, Apr. 2020.

[4] Z. B. Omariba, L. Zhang, and D. Sun, "Review of Battery Cell Balancing Methodologies for Optimizing Battery Pack Performance in Electric Vehicles," IEEE Access, vol. 7, 2019.

[5] V. T. Liu and J. R. Chen, "Balancing for Lead-Acid Batteries of Electric Motorcycles," Applied Mechanics and Materials, vol. 764-765, 2015.

[6] L. Technology Corporation, "LTC3305 - Lead-Acid Battery Balancer", Accessed: Dec. 03, 2021. [Online]. Available: http://www.linear.com/tapeandreel/.

[7] M. Daowd, M. Antoine, N. Omar, P. van den Bossche, and J. van Mierlo, "Single switched capacitor battery balancing system enhancements," Energies, vol. 6, no. 4, 2013.

[8] M. Daowd, M. Antoine, N. Omar, P. Lataire, P. van den Bossche, and J. van Mierlo, "Battery management systembalancing modularization based on a single switched 
capacitor and bi-directional DC/DC converter with the auxiliary battery," Energies, vol. 7, no. 5, 2014.

[9] D. Cadar, D. Petreus, T. Patarau, and N. PALAGHITA "Active Balancing Method for Battery Cell Equalization," Acta Technica Napocensis, vol. 51, no. 2, 2010.

[10] Y. Lee, S. Jeon, H. Lee, and S. Bae, "Comparison on cell balancing methods for energy storage applications," Indian Journal of Science and Technology, vol. 9, no. 17, 2016.

[11] A. Tsapras, C. Balas, K. Kalaitzakis, and J. Chatzakis, "A new equalization scheme for series connected battery cells,"

EPE Journal (European Power Electronics and Drives Journal), vol. 19, no. 3, 2009

[12] G. J. May, A. Davidson, and B. Monahov, "Lead batteries for utility energy storage: A review," Journal of Energy Storage, vol. 15, pp. 145-147, 2018.

[13] "NUCLEO-F767ZI - STM32 Nucleo-144 development board with STM32F767ZI MCU, supports Arduino, ST Zio and morpho connectivity - STMicroelectronics." [Online] https://www.st.com (accessed Dec. 03, 2021).

[14] S. Kazadi, M. Thokozile, and K. A. Ogudo, "Design and Monitoring of a Voltage battery sensor of an Uninterruptible Power Supply (UPS) by means of an Arduino," in 2020 IEEE PES/IAS PowerAfrica, Nairobi, 2020.
[15] Arduino, "Arduino Nano - Arduino Official Store," Store.Arduino.Cc/Usa/. 2017.

[16] Allegro MicroSystems, "Thermally Enhanced, Fully Integrated, Hall-Effect-Based High-Precision Linear Current Sensor IC with $100 \mu \Omega$ Current Conductor ACS770xCB 2,' Feb. 2020. [Online]. Available: www.allegromicro.com.

[17] I. Ihsan and A. wahyu Aditya, "Rancang Bangun Battery Monitoring System (BMS) berbasis LabVIEW," JTT (Jurnal Teknologi Terpadu), vol. 9, no. 1, 2021

[18] B. O. Oyebola and V. T. Odueso, "LM35 Based Digital Room Temperature Meter: A Simple Demonstration," Equatorial Journal of Computational and Theoretical Science, vol. 2, no. $1,2017$.

[19] A. Rospawan, J. W. Simatupang, and I. Purnama, "A Simple, Cheap and Precise Microcontroller Based DDS Function Generator," Journal of Electrical and Electronics Engineering, vol. 3, no. 2, pp. 118-121, 2019.

[20] A. Laurentius Michael and S. Joni Welman, "Design and Implementation of AC Mains Voltage Fluctuation Indicator for Home Appliances," International Journal of Electronics and Device Physics, vol. 2, no. 1, Dec. 2018.

[21] "B21NH series." https://zh-tw.echin.com.tw/b21nhseries.html (accessed Dec. 03, 2021). 